\title{
Parents' Emotion-Related Beliefs, Behaviours, and Skills Predict Children's Recognition of Emotion
}

\author{
Vanessa L. Castro ${ }^{a, *}$, Amy G. Halberstadt ${ }^{a}$, \\ Fantasy T. Lozada ${ }^{b}$ and Ashley B. Craig ${ }^{c}$ \\ ${ }^{a}$ North Carolina State University, Raleigh, NC, USA \\ ${ }^{\mathrm{b}}$ University of Michigan, Ann Arbor, MI, USA \\ '3-C Institute for Social Development, Cary, NC, USA
}

Children who are able to recognize others' emotions are successful in a variety of socioemotional domains, yet we know little about how school-aged children's abilities develop, particularly in the family context. We hypothesized that children develop emotion recognition skill as a function of parents' own emotion-related beliefs, behaviours, and skills. We examined parents' beliefs about the value of emotion and guidance of children's emotion, parents' emotion labelling and teaching behaviours, and parents' skill in recognizing children's emotions in relation to their school-aged children's emotion recognition skills. Sixty-nine parent-child dyads completed questionnaires, participated in dyadic laboratory tasks, and identified their own emotions and emotions felt by the other participant from videotaped segments. Regression analyses indicate that parents' beliefs, behaviours, and skills together account for $37 \%$ of the variance in child emotion recognition ability, even after controlling for parent and child expressive clarity. The findings suggest the importance of the family milieu in the development of children's emotion recognition skill in middle childhood and add to accumulating evidence suggesting important age-related shifts in the relation between parental emotion socialization and child emotional development. Copyright (C) 2014 John Wiley \& Sons, Ltd.

Key words: emotion; socialization; parents/parenting; parent-child communication

Children who understand and recognize others' emotions are successful in a variety of socioemotional domains (for reviews, see Halberstadt, Denham, \& Dunsmore, 2001; Halberstadt, Parker, \& Castro, 2013; Trentacosta \& Fine, 2010). For example,

*Correspondence to: Vanessa L. Castro, North Carolina State University, Campus Box 7650, Raleigh, NC 27695-7650, USA. E-mail: vlcastr2@ncsu.edu 
children's emotion understanding is associated with fewer parent- and teacherreported internalizing and externalizing behaviours (e.g., Cook, Greenberg, \& Kusché, 1994; Morgan, Izard, \& King, 2009), greater parent-reported cooperation, assertion, and self-control (Mostow, Izard, Fine, \& Trentacosta, 2002), greater teacher-reported social competence (Rothman \& Nowicki, 2004), and greater displays of prosocial behaviours in the laboratory (Ensor, Spencer, \& Hughes, 2011). Further, the specific skill of emotion recognition accuracy is associated with being liked by peers (Dunsmore, Noguchi, Garner, Casey, \& Bhullar, 2008; Miller et al., 2005), behaving less aggressively in school settings (Denham et al., 2002; Schultz, Izard, \& Bear, 2004), and a number of factors associated with educational success (e.g., Denham et al., 2012; Garner \& Waajid, 2008; Halberstadt \& Hall, 1980).

Although the advantages of understanding and recognizing emotions are clear, we know little about how these abilities develop throughout childhood, particularly within the family context despite the number of emotion socialization researchers who have argued for the importance of the family milieu at this time in children's emotional development (e.g., Eisenberg, Cumberland, \& Spinrad, 1998; Gottman, Katz, \& Hooven, 1996; Lunkenheimer, Shields, \& Cortina, 2007). Middle childhood is specifically interesting because of the intriguing socialization paradox at this age, with parents retaining influence regarding children's socioemotional competence (Freitag, Belsky, Grossmann, Grossmann, \& Scheuerer-Englisch, 1996), and children simultaneously developing greater behavioural autonomy (Wray-Lake, Crouter, \& McHale, 2010). Children at this age also demonstrate cognitive and social advancements that contribute to greater understanding of emotions and social interactions (Eccles, 1999). Moreover, context may be especially important for older children's emotion recognition skill, as children and parents share a history of emotion-related experiences and expectations, all of which are relevant to children's growing emotional repertoires (Klimes-Dougan \& Zeman, 2007). Thus, we chose to examine the influence of parental emotion socialization on children's emotion recognition skill during middle childhood.

We propose a socialization model in Figure 1 with the three likely domains by which parents contribute to children's developing emotion recognition skill within the family: (i) parents' beliefs about children's emotions; (ii) their behaviours with regard to children's emotions; and (iii) their own emotion recognition skill. In the present study, we test the degree to which these three domains relate to children's emotion recognition skill within the family context, and specifically within the parent-child dyad, following recent calls for more dynamic and real-life measurement of emotional processes (e.g., Boiger \& Mesquita, 2012; Halberstadt et al., 2013; Krumhuber, Kappas, \& Manstead, 2013). Below, we discuss why these parent variables are important to children's emotion recognition skill, followed by a description of the complexity in assessing children's emotion recognition skill.

\section{Parents' Emotion-Related Beliefs}

Recent theory and evidence suggest that parents' beliefs about emotion guide a number of parents' emotion-related socialization behaviours (e.g., Dunsmore \& Halberstadt, 1997; Eisenberg et al., 1998). In particular, meta-emotion theory suggests that parents who view emotions as valuable and an opportunity for intimacy engage in behaviours that are instructive, responsive, and encouraging of children's emotions, whereas parents who view emotions as problematic or dangerous tend to deny, ignore, or minimize children's emotions (Gottman et al., 1996). Parents' emotionrelated beliefs may also sufficiently infuse family environments so that they directly 


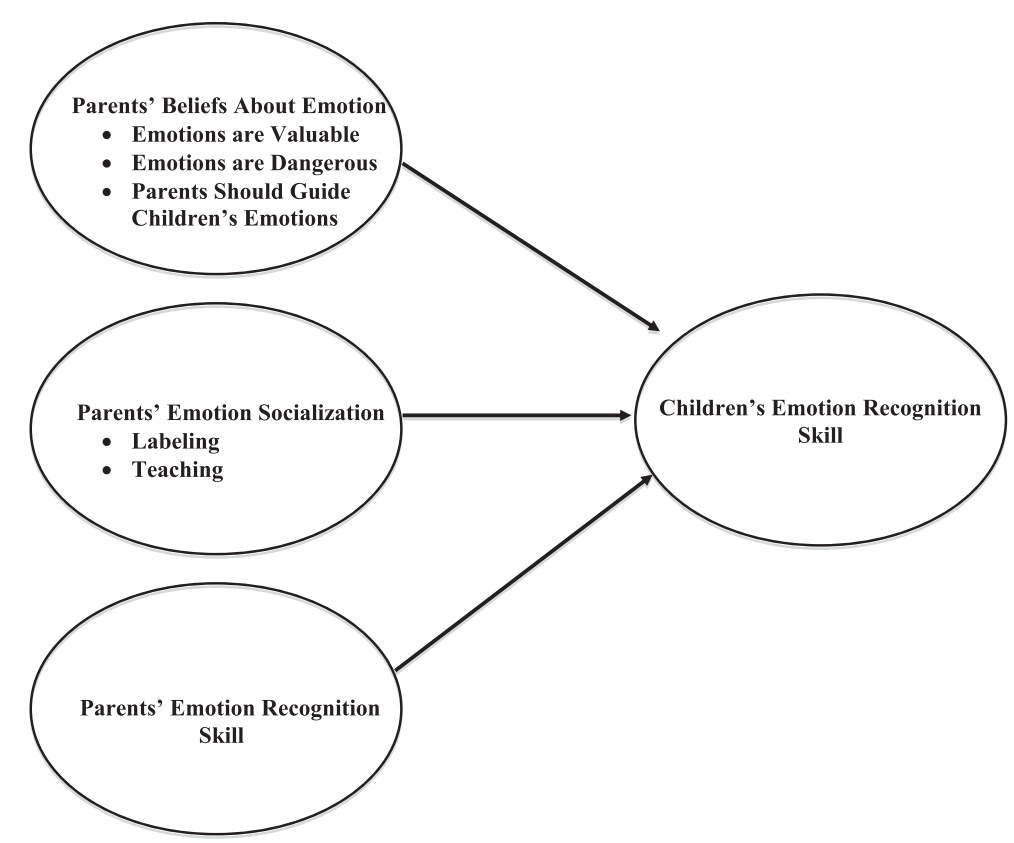

Figure 1. Model of children's emotion recognition as a function of parents' beliefs about children's emotions, emotion socialization behaviours, and own emotion recognition skill.

predict children's skill, for example, coping with emotionally intense events (Halberstadt, Thompson, Parker, \& Dunsmore, 2008), feeling socially competent with peers (Wong, Diener, \& Isabella, 2008), and recognizing others' emotions (Dunsmore, Her, Halberstadt, \& Perez-Rivera, 2009; Perez-Rivera \& Dunsmore, 2011). We focus on the two most relevant belief sets: the value/danger of emotions and the guidance of emotion socialization.

\section{Emotions as valuable and emotions as problematic or dangerous}

The belief that emotions are valuable suggests some awareness and acceptance of emotions. Parents who believe in the value of emotion believe that children benefit from the experience and expression of both positive and negative emotions, and that these emotions provide opportunities for children to learn and develop (Gottman et al., 1996; Parker et al., 2012; Stelter \& Halberstadt, 2011). Such parents are likely to engage in emotion coaching behaviours (Gottman et al., 1996; Lunkenheimer et al., 2007), and we may expect then that parents who value both positive and negative emotions will create environments that are more emotionally expressive, sensitive to, and accepting of children's emotion as compared with parents who do not value emotion; such beliefs may thus provide children with opportunities to learn how to express and identify their own and others' emotions.

In contrast, parents who believe that emotions can be problematic or dangerous for children when experienced frequently or intensely may hide or mask their own emotions in attempts to shield children from observing their emotional experiences (Dunsmore et al., 2009; Halberstadt, Thompson et al., 2008). Although this might initially decrease opportunities for children to learn about emotions, over time a shift may occur as children work harder at knowing what their parents are feeling and thinking because of the subtlety with which emotions are being expressed. This pattern has 
been found in the family expressiveness literature, in which a positive relation between parents' expressiveness and children's emotion recognition skill is evidenced in very young children (Camras et al., 1990) but begins to shift for children in elementary school, with an increasingly negative relation over time (see Halberstadt \& Eaton, 2002, for a meta-analysis). The shift indicates that children growing up with parents who are less expressive become more skilled at recognizing others' emotional expressions compared with children who grow up in more expressive homes. Thus, in the case of parents' beliefs, when parents believe that emotions are problematic or dangerous, they may subsequently mask their emotions, and children may have to work especially hard at knowing what their parents are feeling and thinking owing to the subtlety with which emotions are expressed. This affective climate may thus foster more accurate emotion recognition skill for older children as they become attuned to their parents' unique beliefs and ways of expressing emotion over time. ${ }^{1}$

We also note related findings in middle childhood for children in nonnormative, challenging environments, such as potentially abusive homes. Children in such situations work harder to identify expressions of anger and, thus, eventually become more skilled than children in less challenging environments (Masten et al., 2008; Pollak, Cicchetti, Hornung, \& Reed, 2000; Pollak, Messner, Kistler, \& Cohn, 2009). Although such environments may also contribute to perceptual biases (for recent meta-analysis see Luke \& Banerjee, 2013), it appears that some degree of environmental challenge may inadvertently stimulate children's emotional development and promote adaptation to that environment.

\section{Guidance of children's emotions}

Parents who believe they are responsible for helping children learn about emotions emphasize their own agency in children's emotional development (Denham \& Kochanoff, 2002; Dunsmore \& Karn, 2001, 2004). Thus, parents who believe that guidance is important may provide more explicit instruction regarding the causes, consequences, and nature of emotions compared with parents who believe that guidance is less important; indeed, the belief in parental guidance predicts greater emotion labelling and knowledge in young children aged 4 to 6 years (Dunsmore \& Karn, 2001, 2004). However, as children become older, parental guidance may predict less skill in children's recognition of parents' emotions (Dunsmore et al., 2009), perhaps because such guidance interferes with children's recognition of parents' emotions or alternatively because parents are responding proactively when they see their children falling behind in skill by this age. Thus, by middle childhood, parents' beliefs in the importance of guiding children may either disrupt children's development of skills or reflect parents' concerns when their children have not sufficiently developed these skills.

\section{Parents' Emotion-Related Behaviours}

In addition to parents' beliefs about emotion, parents' active acknowledgement and instruction regarding children's emotions may also predict children's development of emotion recognition skill. We included the two types of instructive behaviours found in previous research that are most likely to relate to children's emotion recognition skill: labelling and teaching.

Labelling is defined as occurring when a parent explicitly identifies what the child or another person is feeling (Denham \& Kochanoff, 2002; Havighurst, Wilson, Harley, Prior, \& Kehoe, 2010) and is related to enhanced emotion regulation skills (Eisenberg et al., 2001), lower amounts of internalizing behaviours in the classroom (Denham, Mitch-Copeland, Strandberg, Auerbach, \& Blair, 1997), and greater overall 
social competence with peers (Denham et al., 1997). Teaching is defined as occurring when a parent explicitly points out the causes and consequences of an emotional experience (Dunn \& Brown, 1994; Gottman et al., 1996; Parke, 1994) and is related to greater emotion understanding in children (Garner, Jones, Gaddy, \& Rennie, 1997; Havighurst et al., 2010), lower levels of parent- and teacher-reported internalizing and externalizing behaviours (Havighurst et al., 2010; Sales \& Fivush, 2005), and children's academic adjustment (Gottman et al., 1996). Thus, we predicted that both labelling and teaching behaviours would relate positively to children's skill in recognizing parents' emotions.

\section{Parents' Emotion-Related Skill}

The literature on children's understanding and recognition of emotion has focused on emotion-related beliefs and socialization behaviours, yet parents' own emotion recognition skill may also predict children's skill, through both direct and indirect associations with parents' beliefs and behaviours. Passive gene-environment correlations suggest that parents' own emotion recognition abilities contribute to the affective climate of the family, thus influencing the context in which children develop emotion recognition skill (Rutter, 2006). Additionally, there is some evidence to suggest that parents' own emotion-related skills influence children's emotion-related skills (e.g., Daly, Abramovitch, \& Pliner, 1980; Perlman, Camras, \& Pelphrey, 2008); however, these findings have often focused on parents' skills in regulating or expressing emotion and not parents' skills in recognizing emotion, particularly their skill in recognizing children's emotions. It is possible that parents who have greater emotion recognition accuracy are more likely to have the skills needed to accurately respond to children and, thus, guide children's emotion understanding more effectively.

\section{Children's Emotion Recognition Skill}

Most studies examining emotion recognition within family contexts are directed toward children in the preschool years (e.g., Camras et al., 1990; Garner et al., 1997; Havighurst et al., 2010) and, as such, use fairly simplistic measures of emotion recognition in order to be developmentally appropriate. As children's emotionrelated skills continue to develop throughout elementary school (e.g., Larsen, To, \& Fireman, 2007; Pons, Harris, \& de Rosnay, 2004; Vitulić, 2009), it is important to utilize measures that adequately capture the increasing complexity of elementary school-aged children's skills. Further, increased interest in ecological measurement is directing attention away from still poses of emotions and highlights the importance, particularly for older children and adults, of measuring real-time emotion recognition within interpersonal contexts (Boiger \& Mesquita, 2012; Halberstadt et al., 2013). To address these issues, we chose to study children's skill in recognizing parents' emotions more dynamically, as such skill is more representative of real-life emotional transactions within parent-child relationships than standardized, still posed measures of general emotion recognition.

\section{The Present Study}

To date, no study has included parents' emotion-related beliefs, behaviours, and skills together when predicting children's emotion recognition. Thus, in this study, we tested whether parents' beliefs about children's emotions, emotion-related 
socialization behaviours, and emotion recognition abilities would be associated with children's emotion recognition. We included the three factors in one regression model to assess each factor's unique contributions in explaining children's emotion recognition skill. We hypothesized that children's accuracy in recognizing parents' emotions would be positively related to parents' beliefs about the value and danger of emotions, and negatively related to parents' belief that parents should guide children's socioemotional development. Second, we predicted that children's accuracy in recognizing parents' emotions would be positively associated with parents' use of labelling and teaching behaviours. Third, we predicted that parents' recognition of children's emotions would relate positively to children's recognition of parents' emotions.

\section{METHOD}

Parents' beliefs about children's emotions were measured using a self-report questionnaire. Parents' emotion socialization behaviours were observed during a board game designed to evoke emotion-related conversation. Emotion recognition for both parents and children was measured using an in vivo interaction task. To control for the potential confound between parent-child sending and receiving abilities, we included a measure of both parents' and children's expressive clarity assessed by a group of naïve coders.

\section{Participants}

Participants were 69 parent-child dyads. Parents ranged from 28 to 53 years of age $\left(M_{\text {age }}=39.15, S D=4.94 ; 79 \%\right.$ mothers $)$. Children ranged from 8 to 11 years of age $\left(M_{\text {age }}=9.57, S D=0.71 ; 52 \%\right.$ daughters $)$. Family ethnicities were African American $(n=34)$, European American $(n=5)$, and Lumbee American Indian $(n=30)$. Parents' education levels were as follows: 22 with a high school degree, 25 with a college degree, and 22 with a graduate degree or some post-college education. Family annual income ranged from $\$ 8500$ to $\$ 180,000\left(M_{\text {income }}=\$ 75,404, S D=\$ 42,235\right)$. Most families included two parents in the home $(n=51)$, with other family structures also represented (single parent, $n=7$; divorced, $n=8$; separated, $n=3$ ). The parentchild dyads were participating in a larger study conducted in three small Southeastern cities (see Stelter \& Halberstadt, 2011), and parents were recruited to participate in game playing and conversations with their children in a university setting through announcements and flyers posted in the community, invitations passed to parents during recreational sports practices, and emails via online web listings, university alumni organizations, and directories of participation in previous research studies. The families appear to represent their communities well and, in comparison with data for the counties in which they live, indicate a (relatively) low-risk sample.

\section{Procedure}

Following informed consent by parents and assent by children, parents completed a questionnaire assessing parental beliefs about children's emotions while children were interviewed by a researcher for another task not relevant to this study. Parent-child dyads then engaged in two activities which were video-recorded, with one camera recording each participant. The first activity was a game involving emotion-related conversation, and the second was a problem-solving discussion that was 
subsequently used as stimuli for the self- and other-rating measures of emotion recognition. Following the session, parent-child dyads were thanked and compensated for their time. A racially diverse team of research assistants assisted with all data collection and coding procedures.

\section{Measures}

Parents' beliefs about children's emotions

Five subscales of the Parents' Beliefs About Children's Emotions Questionnaire (PBACE; Halberstadt, Dunsmore, Parker, Beale, Thompson, \& Bryant, 2008) were of particular interest for this study. The Value dimension contains three subscales: Positive Emotions are Valuable ('It is important for children to express their happiness when they feel it', 10 items, $\alpha=0.80)$, Negative Emotions are Valuable ('The experience of anger can be a useful motivation for action', 12 items, $\alpha=0.79$ ), and Emotions are Dangerous ('Children who feel emotions strongly are likely to face a lot of trouble in life', 13 items, $\alpha=0.78$ ). The Guidance dimension contains two subscales: Parents Guide ('It's a parent's job to teach children about happiness', 9 items, $\alpha=0.76$ ) and Children are Capable ('Children can figure out how to express their feelings on their own', 8 items, $\alpha=0.84$ ). Because the two scales regarding the value of positive and negative emotion were conceptually and empirically related, $r(67)=0.29, p=0.014$, we created a combined Emotions are Valuable scale (22 items; $\alpha=0.81$ ). Because the two Guidance scales were also conceptually and empirically related, $r(67)=-0.37, p=0.002$, we reverse-scored the Children are Capable scale and created a combined Parents Should Guide scale ( 17 items; $\alpha=0.84$ ). For all items, parents rated their level of agreement with each item using a 6-point Likert-type scale from strongly disagree (1) to strongly agree (6).

The PBACE subscales were derived from a series of exploratory and confirmatory factor analyses using oblique rotations with 1108 mothers and fathers from three ethnicities (African American, European American, and Lumbee American Indian) following focus groups with those same ethnicities to identify items that resonated broadly for parents (Parker et al., 2012; Stelter \& Halberstadt, 2011). Evidence of construct validity across multiple ethnic groups has been demonstrated by associations with parents' socialization behaviours such as parents' discussions of emotional events and emotional expression (Dunsmore et al., 2009; Halberstadt, Thompson et al., 2008; Perez-Rivera \& Dunsmore, 2011) and with children's emotional coping, self-construals, and feelings of security (Halberstadt, Thompson et al., 2008; Her \& Dunsmore, 2011; Stelter \& Halberstadt, 2011).

\section{Parents' socialization behaviours}

Parents and children were video-recorded while playing a board game designed to evoke emotion-related conversation for approximately 15 minutes. The game, LifeStories ${ }^{\circledR}$, encourages families to talk about life experiences (e.g., 'Describe a good time you had with your family' and 'Describe one of your favorite childhood toys or games') and is played much like other board games where players roll dice, move a specified number of spaces on the board, and select cards from specific decks. Players were able to select cards from three decks designed to elicit discussion, including six cards that were added to elicit discussions more specific to emotion (e.g., 'Tell about a time the other player made you feel angry'). Additionally, players could select from a fourth deck of cards twice in the game as an alternative to answering other card questions or if they were unable to come up with an example experience with which to respond. 


\section{Coding of parents' behaviours}

The transcribed conversations were coded for frequency of emotion-related socialization behaviours by three-person multi-ethnic teams, with each coder assigned to two-thirds of the game conversation, so that all conversations were coded twice. Coders were trained until they reached reliabilities at or exceeding kappa of 0.80 , with interim reliabilities calculated to assess for any observer drift, and final reliability assessed for one-third of all transcripts. Disagreements were resolved by coder consensus (manuals available from the authors).

Labelling was defined as instances in which the parent labelled or named either her or his emotional experience or that of their child. For example, if a parent said, 'Your father was so mad!', the emotion word 'mad' was considered a label $\left(M_{\text {kappa }}=0.84\right)$. Teaching was defined as instances during which the parent discussed the causes and/or consequences of emotion by providing a rationale (e.g., 'I'm irritated because I have to keep calling you'; $M_{\text {kappa }}=0.97$ ). Coding for both labelling and teaching behaviours occurred only when the parent explicitly provided an emotion label. Labelling and teaching codes were mutually exclusive. Labelling was only coded when parents used an emotion word but did not provide an explanation about the cause and consequence for the emotion. Teaching was coded only when a parent used both an emotion word and an explanation.

\section{Parent and child emotion recognition}

Parent-child dyads engaged in a 7-minute problem-solving discussion of an ongoing situation which they agreed was conflictual (e.g., homework, bedtime, sibling relationships), following Gunslicks-Stoessel and Powers (2008) and Welsh and Dickson (2005). Dyads were instructed to discuss a second topic if they succeeded in resolving the first.

Immediately following the discussion, research assistants selected the middle 3 minutes and identified 18 ten-second video clips that would then be judged by the parent and the child separately. Parents and children were taken to separate rooms to first watch their own video clips and then to watch the video clips of the other. After each video clip, participants circled the emotions they felt during that video clip on a provided answer sheet. Emotions were clustered into six emotion categories: Happy (consisting of happy, pleased, proud), Curious (curious, interested, surprised), Anxious (anxious, worried, afraid), Mad (irritated, frustrated, mad), Sad (sad, hurt), and None. Participants were allowed to select multiple emotion categories, although this was a rare event ( $4.03 \%$ of ratings). After completing the task for oneself, the dyad members switched rooms and judged the other person's video clips, using the same rating procedure. Thus, each participant reported their own feelings (or lack of feeling) during each video clip, and what the other dyad member was feeling (or not feeling) during the same video clip. Although the conflict discussion task was designed to elicit emotionally arousing dialogue, parents and children were able to engage in relatively calm and pleasant discussions that did not reflect highly intense, negative affect. They did report a range of emotions; thus, the task seemed to invite variability in responses. Specifically, parents reported the following frequencies in feeling Happy (20\%), Curious (35\%), Anxious (8\%), Mad (20\%), Sad (1\%), and No emotion (16\%); and children reported the following frequencies in feeling Happy (26\%), Curious (21\%), Anxious (11\%), Mad (14\%), Sad (8\%), and No emotion (20\%).

Emotion recognition scores were then calculated for parents and children on the basis of agreement between what the individual self-reported during the video clip and what the other person judged that individual to be feeling. Scores were determined using an accuracy scoring paradigm. Participants received full credit 
for agreement and partial credit of 0.5 when answers did not match but were at least of shared valence (e.g., if the mother reported that she felt 'sad', and the child reported that her mother felt 'angry'), following Denham (1986) and Dunsmore and Smallen (2001). Partial credit was also awarded if multiple emotion categories were selected and at least one matched what the partner reported or vice versa (e.g., if the child judged her mother to be 'happy' and 'curious', and the mother reported feeling 'curious'). Mean emotion recognition scores for parents and children were calculated by averaging values across all 18 clips, resulting in potential scores ranging from 0 (no agreement) to 1 (perfect agreement). Identifying emotions of others in vivo is generally thought to be a challenging task for adults and children alike, and our task was no different, with mean score accuracy in our sample consistent with other measures of accuracy between familiar others (e.g. Ickes, 2011).

\section{Parent and child expressive clarity}

Because interpersonal perception accuracy in dyadic paradigms is always necessarily confounded by the sending skill of the partner, an individuals' accuracy may be because they are more accurate in recognizing their partner's emotions or because their partner is more expressive and thus more easily decoded (Hall, Rosip, LeBeau, Horgan, \& Carter, 2006; Noller, 2001; Snodgrass, Hecht, \& Ploutz-Snyder, 1998). To control for this potential confound, an objective rating of expressive clarity was obtained for each parent and child. Ten naïve observers viewed the same stimuli presented to parents and children and completed the same emotion recognition task. Expressive clarity was calculated as a ratio value, with the numerator representing the highest number of observers that agreed upon a judgment, and the denominator representing the total number of observers for that clip. Thus, if the 10 observers agreed upon a judgment (e.g. anger), then the message rated high on clarity and received a 10/10 score or a value of 1.0. If instead only six raters agreed on a judgment, then the message would receive a score of $6 / 10$ with a value of 0.60 . Expressive clarity was averaged across clips within each participant. Greater values indicate greater expressive clarity. This method of calculating expressive clarity is consistent with previous coding schemes used in the affective sensitivity literature (cf. Noller, 2001). Because we cannot know exactly what the participants were feeling, as this is dependent upon their knowing what they are feeling and being willing to report it, this type of measure is considered the next best option, as it provides a clean measure of expressive ability.

\section{RESULTS}

\section{Preliminary Analyses}

Parents' value and guidance beliefs demonstrated normal distributions. However, as expected of count data, the distribution of parents' labelling behaviours was skewed and leptokurtic. Because a square root transformation did not substantially alter normality, and because all assumptions for linear regression were met (Cohen, Cohen, West, \& Aiken, 2003), we retained the untransformed data in the regression analysis. An examination of outliers revealed an extreme $(3+S D s)$ multivariate outlier on the dependent variable of children's emotion recognition. To maintain the integrity of the distribution and reduce unwarranted outlier influence, this extreme outlying value was replaced with a child emotion recognition value of +2 SDs (Field, 2009). This replacement did not alter any of the independent-dependent variable associations. Means and standard deviations for emotion-related beliefs, 
socialization behaviours, expressive clarity (parent and child), and emotion recognition skill (parent and child) are reported in Table 1 along the diagonal.

Because our sample contained participants from three different ethnicities and two genders, we examined potential effects of ethnicity and gender on children's emotion recognition. Ethnicity, parent gender, and child gender were all initially entered into the first step of the model detailed below. ${ }^{2}$ Ethnicity was not related to children's emotion recognition $(p=0.710)$ and remained a nonsignificant predictor at all steps when entered into the regression models below. Neither parent nor child gender was related to children's emotion recognition ( $p s=0.967$ and 0.938 , respectively) and remained nonsignificant predictors at all model steps. To enhance parsimony, ethnicity, parent gender, and child gender were omitted from the analyses described below. ${ }^{3}$

The children in our sample also varied somewhat in age, and such variation may contribute to children's level of emotion recognition skill. Thus, we examined whether child age predicted children's emotion recognition by entering child age into the first step of the model detailed below. Effects relating to child age were nonsignificant at this initial step $(p=0.817)$, and child age remained a nonsignificant predictor at all subsequent steps. Thus, child age was also omitted from the final model.

To ensure that our model was not influenced by additional family-level characteristics, we also examined the potential effects of parent marital status, number of parents at home, and parents' education on children's emotion recognition. Results from a one-way ANOVA with marital status as a between-subjects factor revealed no significant differences in children's emotion recognition between families with parents who were married, single, divorced, or separated, nor were there significant differences for analyses with one- versus two-parent homes. To test the effect of parent education on children's emotion recognition, education was entered into the first step of the regression model described below. Parent education was not related to children's emotion recognition in the initial model step $(p=0.882)$ and remained nonsignificant at subsequent steps. Moreover, the addition of education into the regression model did not alter the significance or direction of any of the predictors. Thus, parent marital status, number of parents in the home, and parent education were also omitted from the analyses detailed below.

Intracorrelations reported in Table 1 indicate that the beliefs that Emotions are Valuable, Emotions are Dangerous, and Parents Should Guide were unrelated. The two socialization behaviours were moderately positively correlated, suggesting that the more parents engaged in labelling, the more likely they were to also engage in teaching. The belief that Parents Should Guide, the socialization behaviour of labelling, and parents' skill in recognizing children's emotions were significantly correlated with children's recognition of parents' emotions.

\section{Parents' Beliefs, Behaviours, and Skills in Relation to Children's Emotion Recognition}

To test the collective influence of parents' beliefs, behaviours, and emotion recognition skill on children's emotion recognition skill, we conducted a hierarchical regression model in which each group of predictors (beliefs, behaviours, and skills) was regressed onto children's recognition of parents' emotions. In the first step, parent expressive clarity was entered to control for the potential confound that some parents may be easier to judge than others. In the second step, we entered the beliefs that Emotions are Valuable, Emotions are Dangerous, and Parents Should Guide, and in the third step, we entered labelling and teaching. In the fourth step, we entered parents' skill in recognizing children's emotions and child expressive clarity as a control for the potential 


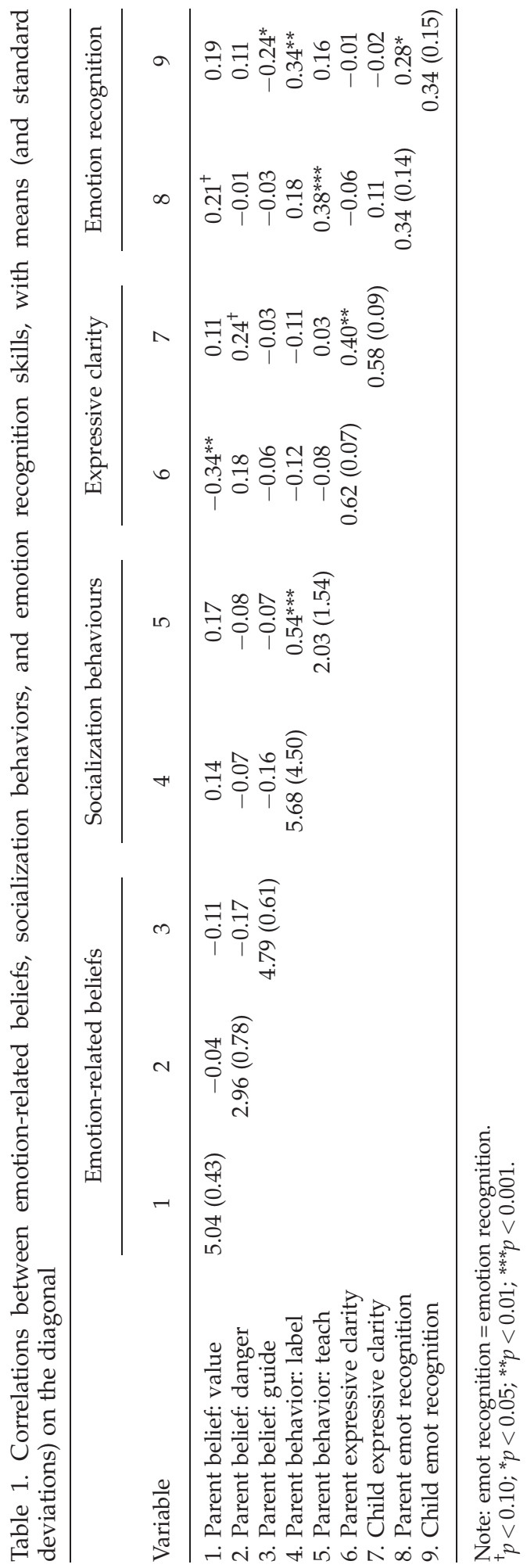


confound that some children may be easier to judge than others. Each step was assessed for statistical significance; within each step, individual variables were evaluated (Table 2).

The overall model was significant, $F(8,48)=3.50, p=0.003, R^{2} \Delta=0.10$. Parent expressive clarity was not significantly related to children's recognition of parents' emotions, $\beta=-0.05, t(56)=-0.34, p=0.736$, and remained nonsignificant at subsequent steps. The addition of the beliefs that Emotions are Valuable, Emotions are Dangerous, and Parents Should Guide in the second model step resulted in a significant change, $F(4,52)=3.97, p=0.007, R^{2} \Delta=0.23$. The beliefs that Emotions are Dangerous and Parents Should Guide were uniquely related to children's recognition of parents' emotions, over and above parent expressive clarity, $\beta \mathrm{s}=0.28$ and $-0.32, t s(56)=2.23$ and $-2.51, p s=0.030$ and 0.015 , respectively. These results remained significant at subsequent steps. The belief that Emotions are Valuable was not significantly related to children's recognition of parents' emotions, $\beta=0.09, t(56)=0.67, p=0.506$, and remained nonsignificant at subsequent steps.

The addition of labelling and teaching in the third model step failed to result in a significant change, although the model step remained significant, $F(6,50)=3.12$, $p=0.011, R^{2} \Delta=0.04$. Neither behaviour was related to children's emotion recognition, $\beta \mathrm{s}=0.22$ and $-0.03, \mathrm{ts}(56)=1.48$ and $-0.19, p \mathrm{~s}=0.146$ and 0.853 , respectively. These factors remained nonsignificant in the fourth step.

The addition of parents' emotion recognition skill and child expressive clarity (as a control for some children being easier to judge than others) in the fourth and

Table 2. Hierarchical regression model predicting children's recognition of parents' emotions

\begin{tabular}{|c|c|c|c|c|}
\hline Predictor variables & $R^{2}$ & $B$ & $S E(B)$ & $\beta$ \\
\hline Step 1 & 0.00 & & & \\
\hline Parent expressive clarity & & -0.09 & 0.26 & -0.05 \\
\hline Step 2 & $0.23^{* *}$ & & & \\
\hline Parent expressive clarity & & -0.16 & 0.25 & -0.08 \\
\hline Emotions are valuable & & 0.03 & 0.25 & 0.09 \\
\hline Emotions are dangerous & & 0.05 & 0.02 & $0.28^{*}$ \\
\hline Parents should guide & & -0.07 & 0.03 & $-0.32 *$ \\
\hline Step 3 & $0.27^{*}$ & & & \\
\hline Parent expressive clarity & & -0.10 & 0.25 & -0.05 \\
\hline Emotions are valuable & & 0.03 & 0.04 & 0.08 \\
\hline Emotions are dangerous & & 0.05 & 0.02 & $0.28^{*}$ \\
\hline Parents should guide & & -0.06 & 0.03 & $-0.28^{*}$ \\
\hline Parent labelling & & 0.01 & 0.00 & 0.22 \\
\hline Parent teaching & & -0.00 & 0.01 & -0.03 \\
\hline Step 4 & $0.37^{* *}$ & & & \\
\hline Parent expressive clarity & & -0.03 & 0.26 & -0.02 \\
\hline Emotions are valuable & & 0.01 & 0.04 & 0.02 \\
\hline Emotions are dangerous & & 0.04 & 0.02 & $0.26^{*}$ \\
\hline Parents should guide & & -0.07 & 0.03 & $-0.32 *$ \\
\hline Parent labelling & & 0.01 & 0.00 & 0.22 \\
\hline Parent teaching & & -0.01 & 0.01 & -0.14 \\
\hline Child expressive clarity & & -0.12 & 0.20 & -0.08 \\
\hline Parent emotion recognition & & 0.34 & 0.13 & $0.35^{*}$ \\
\hline
\end{tabular}

Note: parent and child expressive clarity serve as controls for the potential confounds that some children and parents may be easier to judge than others.

${ }^{*} p<0.05 ;{ }^{* *} p<0.01$. 
final step resulted in a significant change, $F(8,48)=3.50, p=0.003, R^{2} \Delta=0.10$. Parents' own emotion recognition was significantly positively related to children's emotion recognition, over and above parent and child expressive clarity, the beliefs that Emotions are Valuable, Emotions are Dangerous, and Parents Should Guide, and parents' labelling and teaching behaviours, $\beta=0.35, t(56)=2.70, p=0.010$. Child expressive clarity was not significantly related to children's recognition of parents' emotions, $\beta=-0.08, t(56)=-0.64, p=0.526$.

After controlling for parent and child expressive clarity, parents' beliefs that Emotions are Valuable, Emotions are Dangerous, and Parents Should Guide, parents' labelling and teaching behaviours, and parents' own emotion recognition skill together accounted for $36.9 \%$ of the variance in children's emotion recognition.

\section{DISCUSSION}

The present study sought to examine whether parents' beliefs about children's emotions, emotion-related socialization behaviours, and emotion recognition skill predict children's emotion recognition skill. As predicted, the belief that parents should guide children's emotion was negatively correlated with children's emotion recognition skill, and parents' labelling socialization behaviour and emotion recognition skill were both positively correlated with children's emotion recognition skill. In the regression model including all three parent socialization domains, the significant effects for parents' beliefs about guidance and parents' recognition skill persisted, and the parental belief that emotions are problematic or dangerous also emerged as significantly positively related to children's emotion recognition. Together, these factors explained one-third of the variance in children's emotion recognition skill. These results illustrate the importance of parental socialization in the development of children's emotion recognition skill, and specifically within the family.

The negative relation between parents' belief in the guidance of children's emotional development and children's emotion recognition is consistent with previous findings (Dunsmore et al., 2009), suggesting a shift by third grade in the utility of parents' guidance of socioemotional development, and children's skill in recognizing their parents' emotions. It may be that by third grade, parents who believe they are responsible for children's emotional development provide 'too much' emotion socialization; parents may be guiding children in a manner that limits children's involvement in their own development. Further support for this interpretation could be garnered if parents' guidance beliefs related positively with parents' teaching and labelling behaviours and if these latter variables also related negatively to children's emotion recognition. However, parents' beliefs in the guidance of children's emotional development were unrelated to their labelling and teaching behaviours; moreover, teaching was unrelated to children's emotion recognition, and labelling was positively correlated with children's emotion recognition. Thus, we endorse a more bidirectional interpretation: parents may come to believe they are responsible for guiding their children's understanding of emotion because their children are not yet skilled at recognizing others' emotions. In this case, parents' belief in guidance may be a consequence of children's emotion recognition skill rather than a cause. Given the consistency of this finding across two different paradigms and samples (see also Dunsmore et al., 2009) and recent interest in 'helicopter parenting' (e.g., Schiffrin et al., 2013), it may be useful to invest in longitudinal studies that utilize cross-lagged designs to better identify whether parents' beliefs about guidance at this age lead to over-scaffolding of children or indicate sensitive responsiveness to children who may need additional guidance. 
It may also be useful to explore these relations over time with children of varying competence. The mean scores of the parent-child dyads in our study suggest average competence with regard to emotion recognition, at least in comparison with other studies of close dyads (see Ickes, 2011). Further, our sampling methods assumed some modicum of skill within the families recruited (e.g. parents who were able to provide sport participation for children, participate in religious, community, and other organized activities on a regular basis, and/or were active members of alumni organizations). It will be interesting to examine whether the patterns presented here are replicated in at-risk parent-child dyads.

We also found a positive relation between parents' belief that emotions are problematic or dangerous and children's emotion recognition in the hierarchical regression model. This was interesting in that the bivariate correlation between the belief that emotions are dangerous and children's recognition of parents' emotions, as shown in Table 1, was weak. However, when accounting for parent expressive clarity, parents' belief in the value of children's emotions, and parents' belief in the guidance of children's emotional development, we found that greater belief that emotions are dangerous significantly predicted greater emotion recognition accuracy in children, indicating a potential suppression effect. The additional predictors (i.e. parent expressive clarity, parents' belief in the value of children's emotions, and parents' belief in the guidance of children's emotional development) likely reduced the residual variance in the belief that emotions are dangerous (Horst, 1941; Pandey \& Elliott, 2010), resulting in an increased effect size. Recent arguments surrounding suppressor effects point to the benefits in identifying and including such variables in hierarchical regressions, including more accurate independent variable regression coefficients, improved overall predictive power, and enhanced theoretical accuracy (Pandey \& Elliott, 2010). Thus, the suppression effect may more accurately reflect the complexity of real life and the emotional richness of the familial milieu and points to the validity of theoretical and empirical models that include multiple predictors (i.e. Figure 1) as opposed to models that isolate single predictive factors.

The finding that parents' belief in the danger of emotion relates to children's emotion recognition is consistent with the notion that challenging circumstances may serve to foster emotional growth. In previous research, children have demonstrated both perceptual biases and perceptual sensitivity for specific emotions in highly challenging circumstances such as maltreatment (e.g., Masten et al., 2008; Pollak et al., 2000; Pollak et al., 2009; for a recent meta-analysis, see Luke \& Banerjee, 2013). Those findings highlight two important points regarding children's emotional development: (i) children adapt to environmental demands, and (ii) the degree and direction to which children adapt to challenging environments is influenced by the level of challenge, thus resulting in environmental adaptation that is multidimensional and multidirectional.

Our findings suggest that this phenomenon of children's environmental adaptation may be more widespread and may also occur in response to normative variation in parental beliefs. Parents who believe that emotions are problematic or dangerous are less emotionally expressive overall, thus providing children with little information regarding the expression of emotion (Dunsmore et al., 2009). Although initially associated with emotion recognition deficits, this affective climate may lead children to develop superior emotion recognition abilities over time, as greater attention to microexpressions of emotion are required to determine how their parents are really feeling within familial interactions. Our results with third-grade children add to accumulating evidence of curvilinear age-related patterns between parental emotion socialization and children's emotion-related skills (e.g., Halberstadt \& Eaton, 2002; Morris, Silk, Steinberg, Myers, \& Robinson, 2007); parental behaviours that inhibit 
children's emotion recognition skill in the preschool years may actually work to support skill development during elementary school and beyond. Whether such gains in perceptual sensitivity later result in over-attunement to parents' emotions remains an empirical question. Given the importance of these effects, longitudinal research is needed to determine the age and contexts in which such developmental shifts occur, with attention to the possibility of dynamic and bidirectional relations between parent and child factors over time.

Parents' skill in recognizing children's emotions was also uniquely related to children's recognition of parents' emotions; to our knowledge, this is the first study to assess the role of parents' skill as a contributor to children's skill. It makes sense that parents need at least a certain modicum of skill before helping their children acquire the same abilities; otherwise, it would be very difficult to accurately teach children how to recognize others' emotions. Indeed, parents' teaching behaviours were moderately positively related to their emotion recognition skill, which may also explain why the instructive skills did not emerge as separate, unique contributors to children's emotion recognition skill. That parents' emotion recognition skill is associated with children's emotion recognition skill has implications for fostering improved communication and affective understanding in the parent-child relationship; family interventions may want to develop parents' recognition and understanding of children's emotions as well as developing children's skills directly.

Neither parents' labelling nor teaching behaviours were uniquely related to children's emotion recognition in the regression model, despite a significant moderate correlation between labelling and children's emotion recognition. As noted above, parents' teaching behaviours were moderately correlated with parents' emotion recognition skill. It is possible that such skills are more directly related to children's emotional development at this particular developmental period of middle childhood; such a possibility may have dampened the unique contributions of parents' teaching and labelling behaviours in our model. Additionally, as can be seen from Table 1, our lack of relations are not due to ceiling or floor effects in the frequency of parents' labelling and teaching behaviours. It is possible that these behaviours provide children with information regarding emotional scripts (knowledge about situations and general responses to those situations) rather than either the motivational lens to know more information by looking and listening or the perceptual knowledge itself garnered from the nonverbal cues. Thus, further research exploring the difference between knowledge of general emotion scripts and more perceptual tasks of identifying facial expressions and voice tone in relation to teaching and labelling may be warranted.

The development of emotion recognition is often studied in very young children, yet this skill continues to develop throughout childhood; children's understanding of emotion becomes more complex and integrated as children mature cognitively and gain experience and expertise in social interactions (Halberstadt et al., 2013). Our results point to the utility in not only studying emotion recognition skills in ages beyond early childhood but also in studying the ways in which parents' adapt their socialization strategies to meet such changes in child skill. We hope that our results serve as a call for parents to continue to think about emotional intelligence in the middle years of childhood.

\section{Limitations and Strengths}

Although large for this type of dyadic emotion recognition paradigm (e.g., Dunsmore et al., 2009; Noller \& Gallois, 1986), our sample is still relatively small, 
and sample size may decrease detection of subtle effects. Given that some of our nonsignificant findings included relatively moderate sized beta coefficients (i.e. labelling behaviours), it is possible that a larger sample would find such effects to be significant. However, small sample size does not preclude interpretation, as the relations we found together accounted for $37 \%$ of the variance. This finding is both robust and compelling. The fact that these factors together contribute such a large amount of variance in explaining children's emotion recognition supports the model put forth by Eisenberg et al. (1998) that multiple parental factors contribute to children's emotional development.

We note that the recorded conflict discussions may not have elicited strong levels of emotional expression in either parents or children. However, many communications between parents and children may initially occur at low expressive levels, and recognizing these low-intensity emotions before intense emotions are felt may be important for maintaining family harmony.

Further, because of the spontaneous nature of expressions within the conflict discussions, the emotion recognition task was likely more difficult for parents and children to complete compared with more traditional measures of general emotion recognition skill (e.g., Naab \& Russell, 2007). However, rather than excluding spontaneous expressions as valuable measures of emotion recognition, we think this highlights the difficulty in judging the expressions that predominate in everyday life and the importance of including such expressions. Our measure of emotion recognition utilizing parents' and children's spontaneous expressions was appropriate given that our interests were in emotional development within the family context.

With regard to our measurement of parental socialization behaviours, the board game task was designed to elicit emotion-related discussion in relation to shared life experiences between parent-child dyads and, thus, may not reflect parents' typical or complex emotion socialization behaviours. Specifically, parents may not directly use emotion words or terms to teach children about the causes and consequences of emotion in daily interactions but instead may respond to a child's emotion expression with a combination of nonverbal behaviours and general statements of inquiry. Children likely learn from parents' nonverbal displays of emotion, such as smiling, crying, and voice tone, during ongoing interactions (Dunsmore \& Halberstadt, 1997). Parents' nonverbal expressiveness style certainly influences children's emotion recognition skills (see a meta-analysis by Halberstadt \& Eaton, 2002). Parents' nonverbal displays may be particularly salient in middle childhood, as parents may increasingly rely on subtle nonverbal cues, as opposed to explicit emotion labels, to teach children about emotions. Thus, it is possible that the emotion socialization behaviours did not predict children's emotion recognition skill because parents' nonverbal communications were not measured. Future research would benefit from examining the nonverbal richness with which parents' emotion-related messages are delivered to children.

It is also possible that the game invited parents who would not normally use labelling or teaching behaviours to do so, thus obscuring differences in teaching and labelling between parents who more naturally weave these behaviours in their day-to-day interactions from those who only do so in laboratory settings. This may also be a problem for other types of parent-child interactions in the laboratory, and so it is important to note the asset of board games' ecological validity and enjoyable nature, which increases likelihood of accessing parents' emotion-related information.

That parents' beliefs and behaviours are not significantly related suggests that the assumption in meta-emotion theory of the confluence of beliefs to behaviours is not always warranted. Rather, the associations between beliefs and behaviours may be complex and dependent upon the specific beliefs, the specific behaviours, and the age of the children. The pattern of parents' beliefs and/or behaviours not always 
predicting children's outcomes has been noted in other studies as well (e.g., Halberstadt, Thompson et al., 2008; Perez-Rivera \& Dunsmore, 2011; Stelter \& Halberstadt, 2011). It is necessary to consider the context in these relations, as beliefs may be more predictive of behaviours in contexts that are emotionally intense and arousing (Halberstadt, Thompson et al., 2008; Stelter \& Halberstadt, 2011). Also, it may be that beliefs and behaviours are more convergent when children are younger, but that parents' behaviours may become more constrained as children move into middle childhood and parents also struggle with children's increased need for autonomy. Clearly, these results highlight a complexity that will have to be further unpacked in future research.

Our model does not account for additional parental factors that likely contribute to children's emotion recognition development, including neurophysiological markers. For example, our model does not account for the extent to which parents' and children's emotion recognition skills are genetically encoded, yet our model does consider some of this variance in the relation between parent emotion recognition skill and child emotion recognition skill. However, future studies should aim not only to replicate our model but also to identify additional biological, cognitive, and social factors within the family milieu that influence and guide children's emotional development.

Finally, although our sample includes two American minority groups not often included in emotion research, the relatively small sample size precludes examination of potential moderating impacts of ethnic group membership on the contributions of parents' emotion-related beliefs, behaviours, and skills on children's emotion recognition. Recent empirical work suggests ethnicity differences in parents' supportive and nonsupportive emotion-related socialization behaviours (Brown, Craig, \& Halberstadt, 2014; Nelson, Leerkes, O'Brien, Calkins, \& Marcovitch, 2012). In at least one study, however, group differences are partially accounted for by parental beliefs about the social consequences of their children's negative emotions (Nelson et al., 2012). These findings suggest that, rather than simply identifying ethnic group differences in family emotion-related processes, our goal might be to search for the cultural factors, frames, and experiences of various ethnic groups that account for group differences (Halberstadt \& Lozada, 2011). As we still know little about the within- and betweengroup variance in models of emotion-related beliefs, socialization behaviours, and skills among parent-child dyads of minority families, future research should continue to answer the call for more research with diverse participants (Hall \& Maramba, 2001; Hartmann et al., 2013; Sue, 1999) and undertake both within- and between-group studies to better understand the cultural nuances related to these processes.

This study design also demonstrates distinctive strengths. Our research utilized mixed methods, including both questionnaire data and observations of parentchild interactions. Another strength is the ecological validity of the tasks; for example, the conflict discussions allow for the unfolding of real emotional expressions over real time. This type of paradigm may be particularly ideal for measuring emotion recognition in older children who are increasingly confronted with rapidly changing and fragmented emotions occurring simultaneously, and who must apply their knowledge to situations that are flooded with changing mixtures of both relevant and irrelevant information.

It may be argued that our emotion recognition task, because of its ecological validity, reflects an idiosyncratic skill specific to the parent-child relationship. Although this paradigm required children to recognize the skill of only one communicator, other contextualized studies utilizing both general and specific emotion recognition tasks indicate that parental socialization beliefs predict children's specific recognition skill beyond children's general recognition skill (Dunsmore et al., 2009). It is likely 
that parents' emotion-related beliefs, behaviours, and skills influence children's internal working models regarding their own emotional behaviours and expectations they have of others' emotions (Dunsmore \& Halberstadt, 1997; Halberstadt \& Lozada, 2011). Thus, we believe that our findings would generalize to children's general emotion recognition abilities, although this interpretation has not been empirically tested and remains a worthwhile avenue for future research.

It is also important to stress that our results reflect a pattern of associations between parent emotion-related beliefs, behaviours, and skill and children's emotion recognition in a relatively low-risk, normative sample of parent-child dyads. As briefly noted above, we do not yet know whether the patterns observed would generalize to families in which children are at socioeconomic or emotional risk. Such work is an important next step in better delineating the ways in which children develop emotional skills within the family context.

In sum, our findings suggest that children develop understanding and recognition of emotion in relation to parents' beliefs about children's emotions, emotion socialization behaviours, and emotion recognition skill. Because children's emotion recognition appears strongly linked with enhanced socioemotional functioning (e.g., Denham et al., 2012; Dunsmore et al., 2008; Ensor et al., 2011; Garner \& Waajid, 2008; Rothman \& Nowicki, 2004), identifying parental factors predictive of children's emotion understanding may help inform parenting programs designed to remediate children's emotion understanding.

\section{Note}

1. It may seem initially that the beliefs that emotions are valuable and emotions are problematic or dangerous are two bipolar ends of one dimension; however, in previous research (and foreshadowing current findings), these beliefs tend to be uncorrelated and have both similar and different trajectories with various parental behaviours, which also suggests independence (e.g., Halberstadt, Thompson et al., 2008).

2. Mean scores and standard deviations for children's recognition skill by ethnicity, parent gender, and child gender are as follows: African American $\left(M_{\mathrm{AA}}=\right.$ $0.34, S D=0.02)$, European American $\left(M_{\mathrm{EA}}=0.32, S D=0.05\right)$, Lumbee American Indian $\left(M_{\mathrm{LAI}}=0.34, S D=0.03\right)$; Mother $\left(M_{\mathrm{M}}=0.34, S D=0.02\right)$, Father $\left(M_{\mathrm{F}}=\right.$ $0.34, S D=0.04)$; Girl $\left(M_{\mathrm{G}}=0.34, S D=0.02\right)$, Boy $\left(M_{\mathrm{B}}=0.34, S D=0.03\right)$. Although these scores may appear low, they are representative of scores derived from similar paradigms (i.e. empathic accuracy between spouses; Ickes, 2011).

3. We did not hypothesize relations between ethnicity or gender and children's emotion recognition, as we had no conceptual reasons to do so, and the extant research on gender effects for children is somewhat mixed (for reviews, see Halberstadt et al., 2013; Hall \& Gunnery, 2013). The small sample size may have precluded identifying these effects; however, demographic effects were not robust enough to even be noted as trends.

\section{ACKNOWLEDGEMENTS}

Research supported by grants \#535372 from the National Institute for Child Health and Human Development and \#1023839 from the National Science Foundation. We thank Julie Dunsmore for her contributions to our ideas and methodology. We thank 
our participants, and the many undergraduates of the Family Affect, Beliefs, and Behaviors Lab and Shardé McNeil in particular, for contributions to coding these data.

\section{REFERENCES}

Boiger, M., \& Mesquita, B. (2012). The construction of emotion in interactions, relationships, and cultures. Emotion Review, 4, 221-229. doi: 10.1177/1754073912439765

Brown, G. L., Craig, A. B., \& Halberstadt, A. G. (2014). Gender differences in parents' emotion socialization behaviors vary by ethnicity and child gender. Under review.

Camras, L. A., Ribordy, S., Hill, J., Martino, S., Sachs, V., Spaccarelli, S., \& Stefani, R. (1990). Maternal facial behavior and the recognition and production of emotional expression by maltreated and nonmaltreated children. Developmental Psychology, 26, 304-312. doi: 10.1037/0012-1649.26.2.304

Cohen, J., Cohen, P., West, S. G., \& Aiken, L. S. (2003). Applied multiple regression/correlation analysis for the behavioral sciences (3rd ed.). Mahwah, NJ US: Lawrence Erlbaum Associates Publishers.

Cook, E. T., Greenberg, M. T., \& Kusché, C. A. (1994). The relations between emotional understanding, intellectual functioning, and disruptive behavior problems in elementaryschool-aged children. Journal of Abnormal Child Psychology, 22, 205-219. doi: 10.1007/ BF02167900

Daly, E. M., Abramovitch, R., \& Pliner, P. (1980). The relationship between mothers' encoding and their children's decoding of facial expressions of emotion. Merrill-Palmer Quarterly, 26, 25-33.

Denham, S. A. (1986). Social cognition, prosocial behavior, and emotion in preschoolers: Contextual validation. Child Development, 57, 194-201. doi: 10.2307/1130651

Denham, S. A., Bassett, H. H., Way, E., Mincic, M., Zinsser, K., \& Graling, K. (2012). Preschoolers' emotion knowledge: Self-regulatory foundations, and predictions of early school success. Cognition E Emotion, 26, 667-679. doi: 10.1080/02699931.2011.602049

Denham, S. A., Caverly, S., Schmidt, M., Blair, K., DeMulder, E., Caal, S., ... Mason, T. (2002). Angry and aggressive children and emotional perspective taking ability. Journal of Child Psychology \& Psychiatry, 43, 901-916. doi: 10.1111/1469-7610.00139

Denham, S. A., \& Kochanoff, A. (2002). "Why is she crying?": Children's understanding of emotion from preschool to preadolescence. In L. F. Barrett \& P. Salovey (Eds), The wisdom in feeling: Psychological processes in emotional intelligence (pp. 239-270). New York: Guilford Press.

Denham, S. A., Mitchell-Copeland, J., Strandberg, K., Auerbach, S., \& Blair, K. (1997). Parental contributions to preschoolers' emotional competence: Direct and indirect effects. Motivation and Emotion, 21, 65-86. doi: 10.1023/A:1024426431247

Dunn, J., \& Brown, J. (1994). Affect expression in the family, children's understanding of emotions, and their interactions with others. Merrill-Palmer Quarterly, 40, 120-137.

Dunsmore, J. C., \& Halberstadt, A. G. (1997). How does family emotional expressiveness affect children's schemas?. New Directions for Child and Adolescent Development, 77, 45-68. doi: $10.1002 / \mathrm{cd} .23219977704$

Dunsmore, J. C., Her, P., Halberstadt, A. G., \& Perez-Rivera, M. B. (2009). Parents' beliefs about emotions and children's recognition of parents' emotions. Journal of Nonverbal Behavior, 30, 121-140. doi: 10.1007/s10919-008-0066-6

Dunsmore, J. C., \& Karn, M. A. (2001). Mothers' beliefs about feelings and children's emotional understanding. Early Education and Development, 12, 117-138. doi: 10.1207/ s15566935eed1201_7

Dunsmore J. C., \& Karn, M. A. (2004). The influence of peer relationships and maternal socialization on kindergartners' developing emotion knowledge. Early Education and Development, 15, 39-56. doi: 10.1207/s15566935eed1501_3

Dunsmore, J. C., Noguchi, R. J. P., Garner, P. W., Casey, E. C., \& Bhullar, N. (2008). Genderspecific linkages of affective social competence with peer relations in preschool children. Early Education and Development, 19, 211-237. doi: 10.1080/10409280801963897 
Dunsmore, J. C., \& Smallen, L. S. (2001). Parents' expressiveness and young children's emotion decoding with parents and unknown adults. The Journal of Genetic Psychology, 162, 478-494. doi: 10.1080/00221320109597497

Eccles, J. S. (1999). The development of children ages 6 to 14. The Future of Children, 9, 30-44. doi: $10.2307 / 1602703$

Eisenberg, N., Cumberland, A., \& Spinrad, T. L. (1998). Parental socialization of emotion. Psychological Inquiry, 9, 241-273. doi: 10.1207/s15327965pli0904_1

Eisenberg, N., Losoya, S., Fabes, R. A., Guthrie, I. K., Reiser, M., Murphy, B., ... Padgett, S. J. (2001). Parental socialization of children's dysregulated expression of emotion and externalizing problems. Journal of Family Psychology, 15, 183-205. doi: 10.1037/0893-3200.15.2.183

Ensor, R., Spencer, D., \& Hughes, C. (2011). "You feel sad?" Emotion understanding mediates effects of verbal abilities and mother-child mutuality on prosocial behaviors: Findings from 2 years to 4 years. Social Development, 20, 93-110. doi: 10.1111/j.1467-9507.2009.00572.x

Field, A. (2009). Discovering statistics using SPSS. Thousand Oaks, CA: Sage Publications.

Freitag, M. K., Belsky, J., Grossmann, K., Grossmann, K. E., \& Scheuerer-Englisch, H. (1996). Continuity in parent-child relationships from infancy to middle childhood and relations with friendship competence. Child Development, 67, 1437-1454. doi: 10.1111/j.14678624.1996.tb01806.x

Garner, P. W., Jones, D. C., Gaddy, G., \& Rennie, K. M. (1997). Low-income mothers' conversations about emotions and their children's emotional competence. Social Development, 6, 37-52. doi: 10.1111/j.1467-9507.1997.tb00093.x

Garner, P. W., \& Waajid, B. (2008). The associations of emotion knowledge and teacher-child relationships to preschool children's school-related developmental competence. Journal of Applied Developmental Psychology, 29, 89-100. doi: 10.1016/j.appdev.2007.12.001

Gottman, J. M., Katz, L. F., \& Hooven, C. (1996). Parental meta-emotion philosophy and the emotional life of families: Theoretical models and preliminary data. Journal of Family Psychology, 10, 243-268. doi: 10.1037/0893-3200.10.3.243

Gunlicks-Stoessel, M. L., \& Powers, S. I. (2008). Adolescents' emotional experience of mother-adolescent conflict predicts internalizing and externalizing symptoms. Journal of Research on Adolescence, 18, 621-642. doi: 10.1111/j.1532-7795.2008.00574.x

Halberstadt, A. G., Denham, S. A., \& Dunsmore, J. C. (2001). Affective social competence. Social Development, 10, 79-119. doi: 10.1111/1467-9507.00150

Halberstadt, A. G., Dunsmore, J. C., Parker, A. E., Beale, K. S., Thompson, J. A., \& Bryant, A., Jr. (2008). Parents' beliefs about children's emotions. Unpublished questionnaire.

Halberstadt, A. G., \& Eaton, K. L. (2002). Socialization of emotion expression and understanding in the family. Marriage and Family Review, 34, 35-62. doi: 10.1300/J002v34n01_03

Halberstadt, A. G., \& Hall, J. A. (1980). Who's getting the message? Children's nonverbal skill and their evaluation by teachers. Developmental Psychology, 16, 564-573. doi: 10.1037/0012-1649.16.6.564

Halberstadt, A. G., \& Lozada, F. T. (2011). Emotion development in infancy through the lens of culture. Emotion Review, 3, 158-168. doi: 10.1177/1754073910387946

Halberstadt, A. G., Parker, A. E., \& Castro, V. L. (2013). Nonverbal communication: Developmental perspectives. In J. A. Hall, \& M. L. Knapp (Eds), Handbook of communication science (Vol. 2). Berlin: Mouton de Gruyter.

Halberstadt, A. G., Thompson, J. A., Parker, A. E., \& Dunsmore, J. C. (2008). Parents' emotion related beliefs and behaviours in relation to children's coping with the 11 September 2001 terrorist attacks. Infant and Child Development, 17, 557-580. doi: $10.1002 /$ icd. 569

Hall, G. C. N., \& Maramba, G. G. (2001). In search of cultural diversity: Recent literature in cross-cultural and ethnic minority psychology. Cultural Diversity and Ethnic Minority Psychology, 7, 12-26. doi: 10.1037/1099-9809.7.1.12

Hall, J. A., \& Gunnery, S. D. (2013). Gender differences in nonverbal communication. In J. A. Hall, \& M. L. Knapp (Eds), Handbook of communication science (Vol. 2). Berlin: Mouton de Gruyter.

Hall, J. A., Rosip, J. C., LeBeau, L. S., Horgan, T. G., \& Carter, J. D. (2006). Attributing the sources of accuracy in unequal-power dyadic communication: Who is better and why? Journal of Experimental Social Psychology, 42, 18-27. doi: 10.1016/j.jesp.2005.01.005 
Hartmann, W. E., Kim, E. S., Kim, J. J., Nguyen, T. U., Wendt, D. C., Nagata, D. K., \& Gone, J. P. (2013). In search of cultural diversity, revisited: Recent publication trends in cross-cultural and ethnic minority psychology. Review of General Psychology. doi: 10.1037/a0032260

Havighurst, S. S., Wilson, K. R., Harley, A. E., Prior, M. R., \& Kehoe, C. (2010). Tuning into kids: Improving emotion socialization practices in parents of preschool children-Findings from a community trial. Journal of Child Psychology and Psychiatry, 51, 1342-1350. doi: 10.1111/j.14697610.2010 .02303

Her, P., \& Dunsmore, J. C. (2011). Parental beliefs about emotions are associated with early adolescents' independent and interdependent self-construals. International Journal of Behavioral Development, 35, 317-328. doi: 10.1177/0165025410397644

Horst, P. (1941). The prediction of personal adjustment. Social Science Research Council Bulletin, 48. New York, NY: Social Science Research Council.

Ickes, W. (2011). Everyday mind reading is driven by motives and goals. Psychological Inquiry, 22, 200-206. doi: 10.1080/1047840X.2011.561133

Klimes-Dougan, B., \& Zeman, J. (2007). Introduction to the special issue of social development: Emotion socialization in childhood and adolescence. Social Development, 16, 203-209. doi: 10.1111/j.1467-9507.2007.00380.x

Krumhuber, E. G., Kappas, A., \& Manstead, A. S. (2013). Effects of dynamic aspects of facial expressions: A review. Emotion Review, 5, 41-46. doi: 10.1177/1754073912451349

Larsen, J. T., To, Y. M., \& Fireman, G. (2007). Children's understanding and experience of mixed emotions. Psychological Science, 18, 186-191. doi: 10.1111/j.1467-9280.2007.01870.x

Luke, N., \& Banerjee, R. (2013). Differentiated associations between childhood maltreatment experiences and social understanding: A meta-analysis and systematic review. Developmental Review, 33, 1-28. doi: 10.1016/j.dr.2012.10.001

Lunkenheimer, E. S., Shields, A. M., \& Cortina, K. S. (2007). Parental emotion coaching and dismissing in family interaction. Social Development, 16, 232-248. doi: 10.1111/j.14679507.2007.00382.x

Masten, C. L., Guyer, A. E., Hodgdon, H. B., McClure, E. B., Charney, D. S., Ernst, M., \& ... Monk, C. S. (2008). Recognition of facial emotions among maltreated children with high rates of post-traumatic stress disorder. Child Abuse E Neglect, 32, 139-153. doi: 10.1016/ j.chiabu.2007.09.006

Miller, A. L., Gouley, K. K., Seifer, R., Zakriski, A., Eguia, M., \& Vergnani, M. (2005). Emotion knowledge skills in low-income elementary school children: Associations with social status and peer experiences. Social Development, 14, 637-651. doi: 10.1111/j.1467-9507.2005.00321.x

Morgan, J. K., Izard, C. E., \& King, K. A. (2009). Construct validity of the emotion matching task: Preliminary evidence for convergent and criterion validity of a new emotion knowledge measure for young children. Social Development, 19, 52-70. doi: 10.1111/j.1467-9507.2008.00529.x

Morris, A. S., Silk, J. S., Steinberg, L., Myers, S. S., \& Robinson, L. R. (2007). The role of the family context in the development of emotion regulation. Social Development, 16, 361-388. doi: 10.1111/j.1467-9507.2007.00389.x

Mostow, A. J., Izard, C. E., Fine, S. E., \& Trentacosta, C. J. (2002). Modeling the emotional, cognitive, and behavioral predictors of peer acceptance. Child Development, 73, 1775-1787. doi: 10.1111/1467-8624.00505

Naab, P. J., \& Russell, J. A. (2007). Judgments of emotion from spontaneous facial expressions of New Guineans. Emotion, 7, 736-744. doi: 10.1037/1528-3542.7.4.736

Nelson, J. A., Leerkes, E. M., O’Brien, M., Calkins, S. D., \& Marcovitch, S. (2012). African American and European American mothers' beliefs about negative emotions and emotion socialization practices. Parenting: Science and Practice, 12, 22-41. doi: 10.1080/15295192.2012.638871

Noller, P. (2001). Using standard content methodology to assess nonverbal sensitivity in dyads. In J. A. Hall, \& F. Bernieri (Eds), Interpersonal sensitivity: Theory, measurement and applications. Mahwah, NJ: Lawrence Erlbaum Associates.

Noller, P., \& Gallois, C. (1986). Sending emotional messages in marriage: Non-verbal behaviour, sex, and communication clarity. British Journal of Social Psychology, 25, 287-297. doi: 10.1111/j.2044-8309.1986.tb00741.x

Pandey, S., \& Elliott, W. (2010). Suppressor variables in social work research: Ways to identify in multiple regression models. Journal of the Society for Social Work and Research, 1, 28-40. doi: 10.5243 /jsswr.2010.2 
Parke, R. D. (1994). Progress, paradigms, and unresolved problems: A commentary on recent advances in our understanding of children's emotions. Merrill-Palmer Quarterly: Journal of Developmental Psychology, 40, 157-169.

Parker, A. E., Halberstadt, A. G., Dunsmore, J. C., Townley, G., Bryant, A., Jr., Beale, K. S., \& Thompson, J. A. (2012). "Emotions are a window into one's heart": A qualitative analysis of parental beliefs about children's emotions across three ethnic groups. Monographs of the Society for Research in Child Development, 77, 1-144. doi: 10.1111/j.1540-5834.2012.00677.x

Perez-Rivera, M. B., \& Dunsmore, J. C. (2011). Mothers' acculturation and beliefs about emotions, mother-child emotion discourse, and children's emotion understanding in Latino families. Early Education and Development, 22, 324-354. doi: 10.1080/ 10409281003702000

Perlman, S. B., Camras, L. C., \& Pelphrey, K. A. (2008). Physiology and functioning: Parents' vagal tone, emotion socialization, and children's emotion knowledge. Journal of Experimental Child Psychology, 100, 308-315. doi: 10.1016/j.jecp.2008.03.007

Pollak, S. D., Cicchetti, D., Hornung, K., \& Reed, A. (2000). Recognizing emotion in faces: Developmental effects of child abuse and neglect. Developmental Psychology, 36, 679-688. doi: $10.1037 / 0012-1649.36 .5 .679$

Pollak, S. D., Messner, M., Kistler, D. J., Cohn, J. F. (2009). Development of perceptual expertise in emotion recognition. Cognition, 110, 242-247. doi: 10.1016/j.cognition.2008.10.010

Pons, F., Harris, P. L., \& de Rosnay, M. (2004). Emotion comprehension between 3 and 11 years: Developmental periods and hierarchical organization. European Journal of Developmental Psychology, 1, 127-152. doi: 10.1080/17405620344000022

Rothman, A. D., \& Nowicki, S., Jr. (2004). A measure of the ability to identify emotion in children's tone of voice. Journal of Nonverbal Behavior, 28, 67-92. doi: 10.1023/B: JONB.0000023653.13943.31

Rutter, M. (2006). Gene-environment interdependence. Developmental Science, 10, 12-18. doi: 10.1111/j.1467-7687.2007.00557.x

Sales, J. M., \& Fivush, R. (2005). Social and emotional functions of mother-child reminiscing about stressful events. Social Cognition, 23, 70-90. doi: 10.1521/soco.23.1.70.59196

Schiffrin, H. H., Liss, M., Miles-McLean, H., Geary, K. A., Erchull, M. J., \& Tashner, T. (2013). Helping or hovering? The effects of helicopter parenting on college students' well-being. Journal of Child and Family Studies, 1-10. doi: 10.1007/s10826-013-9716-3

Schultz, D., Izard, C. E., \& Bear, G. (2004). Children's emotion processing: Relations to emotionality and aggression. Development and Psychopathology, 16, 371-387. doi: 10.1017/S0954579404044566

Snodgrass, S. E., Hecht, M. A., \& Ploutz-Snyder, R. (1998). Interpersonal sensitivity: Expressivity or perceptivity? Journal of Personality and Social Psychology, 74, 238-249. doi: 10.1037/0022-3514.74.1.238

Stelter, R. L., \& Halberstadt, A. G. (2011). Children's feelings of security as affected by parental beliefs about children's emotions and parental stress. Infant and Child Development, 20, 272-287. doi: $10.1002 /$ icd.693

Sue, S. (1999). Science, ethnicity, and bias: Where have we gone wrong? American Psychologist, 54, 1070-1077. doi: 10.1037/0003-066X.54.12.1070

Trentacosta, C. J., \& Fine, S. E. (2010). Emotion knowledge, social competence, and behavior problems in childhood and adolescence: A meta-analytic review. Social Development, 19, 1-29. doi: $10.1111 / j .1467-9507.2009 .00543 . x$

Vitulić, H. S. (2009). The development of understanding of basic emotions from middle childhood to adolescence. Studia Psychologica, 51, 3-20.

Welsh, D. P., \& Dickson, J. W. (2005). Video-recall procedures for examining observational data and subjective understanding in family psychology. Journal of Family Psychology, 19, 62-71. doi: 10.1037/0893-3200.19.1.62

Wong, M. S., Diener, M. L., \& Isabella, R. A. (2008). Parents' emotion related beliefs and behaviors and child grade: Associations with children's perceptions of peer competence. Journal of Applied Developmental Psychology, 29, 175-186. doi: 10.1016/j.appdev.2008.02.003

Wray-Lake, L., Crouter, A. C., \& McHale, S. M. (2010). Developmental patterns in decisionmaking autonomy across middle childhood and adolescence: European American parents' perspectives. Child Development, 81, 636-651. doi: 10.1111/j.1467-8624.2009.01420.x 